\title{
ANTI-ÉDIPO / PSICANÁLISE: UM DEBATE ATUAL
}

Regina Neri

Psicanalista, doutora em teoria psicanalítica pelo Instituto de Psicologia da UFRJ; bolsista recémdoutor do $\mathrm{CNPq}$ junto ao Núcleo de Estudos da Subjetividade da Pós-graduação em Psicologia Clínica, PUC-SP

RESUMO: Buscando inserir o discurso psicanalítico no debate sobre as novas formas de subjetivação, o trabalho encerra uma aposta na fecundidade da interlocução entre a psicanálise e produções discursivas emergentes na contemporaneidade. Propomo-nos a realizar um agenciamento entre o conceito de pulsão em Freud e a formulação de máquina desejante de Deleuze e Guattari.

Palavras-chave: Psicanálise, pulsão, anti-Édipo, máquina desejante.

ABSTRACT: Anti-Oedipus / Psychoanalysis: A current debate. Trying to insert the psychoanalytical discourse into the debate on the new forms of subjectivity, this paper develops an articulation between psychoanalysis and the emerging speech production in these days in order to achieve interconnection between Freud's driving forces and the formulation of Deleuze's and Guattari's desire machines.

Keywords: Psychoanalysis, drive, anti-Oedipus, desiring machine.

Onsiderando a psicanálise uma produção discursiva histórica, cuja contribuição teórica adviria, justamente, do fato de se constituir em um discurso que tenta dar conta de questões emergentes de seu tempo - a crise do sujeito clássico da razão, a crise das identidades fixas que marca a Modernidade — , cremos ser tarefa dos psicanalistas, hoje, tentar estar à altura da radicalidade do gesto fundador. Para tanto, faz-se necessário considerar o texto freudiano como uma obra aberta, cuja genialidade é justamente não ter cedido à tentação de se erigir como um sistema (PONTALYS, 1994), colocando, tal como fez Freud, a psicanálise na escuta de seu tempo.

Foucault em seu texto "O que é um autor” (1983) apresenta a obra freudiana como "fundadora de discursividade". Freud teria produzido, mais que uma obra, um texto transdiscursivo que se abre para uma possibilidade infinita de discursos, desta- 
cando assim a potência da obra freudiana como produção de diferença. Essa perspectiva nos parece fundamental para avaliarmos os possíveis efeitos do texto freudiano na produção discursiva contemporânea. No campo psicanalítico, nos incita a novas interpretações que não tenham a pretensão de reivindicar a verdade sobre o texto freudiano, como parece ter ocorrido com “o retorno a Freud” proposto por Lacan.

Pretendemos evidenciar o debate privilegiado que os discursos sobre a desconstrução do sujeito na contemporaneidade mantém com a psicanálise, a interlocução crítica de Deleuze / Guattari e de Foucault, vindo, em nosso entender, testemunhar sobre o estatuto do texto freudiano como operador de discursividades. Entretanto, queremos igualmente pensar de que modo as críticas formuladas por esses autores abriram, no campo psicanalítico atual, novas possibilidades de leitura da obra freudiana.

A tentativa de articulação pulsão / máquina desejante se apresenta como esboço de um trabalho que visa uma retomada do debate Psicanálise / anti-Édipo, menos em termos de oposição, contradição, e mais em termos de uma interlocução que potencialize novos agenciamentos entre essas obras.

Como afirma Pelbart (1995), o século XX mostrou que é impossível pensar a paisagem contemporânea sem levar em conta a irrupção da psicanálise. Em contrapartida, a psicanálise se revela a cada dia mais impensável sem os influxos que lhe chegam incessantemente dessa mesma paisagem.

\section{DELEUZE / FOUCAULT: UM QUESTIONAMENTO INSTIGANTE}

O pensamento de Deleuze-Guattari / Foucault, por caminhos diferentes e singulares, assinalam, na contemporaneidade, uma ruptura definitiva com os pontos de vista universalisantes e metafísicos sobre o sujeito e o sexo. Ao desconstruírem a categoria de sujeito para pensarem a subjetividade como máquinas de produção desejante ou formas de subjetivação que se produzem em um jogo incessante entre poderes, formações discursivas e agenciamentos libidinais, suas obras endereçam um questionamento instigante para o campo psicanalítico: discurso de subversão do sujeito do cogito cartesiano ou nova metafísica do sujeito e do sexo? Haveria ainda uma ontologia do sujeito na psicanálise? (BORCH-JACOBSON, 1989). Ainda que Freud tenha provocado uma reviravolta na noção de sujeito, sem no entanto recorrer a essa categoria tão cara a Lacan, como comenta Pelbart (2000), não é por ser considerado dividido, descentrado, des-substancializado que o sujeito necessariamente deixa de subsistir na psicanálise.

A obra de Foucault coloca uma questão crucial ao discurso psicanalítico: teoria universal do sujeito, ou produção discursiva histórica? Historicizar o discurso psicanalítico implica em situá-lo dentro dos marcos da produção discursiva do século XIX. Ao criticar a hipótese repressiva que concebe as relações entre o poder 
e a sexualidade como da ordem da repressão — o poder reprime o sexo —, Foucault propõe uma articulação mais complexa entre poder, saber e sexualidade, evidenciando a emergência, no século passado, de uma estratégia do poder que visa menos reprimir a sexualidade do que produzir discursos sobre o sexo. No volume 1 da História da sexualidade, Foucault mostra de que modo o discurso psicanalítico nascente toma lugar nos dispositivos das ciências sexuais de colocação em discurso da sexualidade, apontando para os paradoxos desse discurso emergente. A psicanálise, ao dar voz a uma sexualidade disruptiva à lei, propondo-se a levantar o recalque e articular o desejo incestuoso, formula no coração mesmo dessa sexualidade, como princípio de sua formação e inteligibilidade, o respeito à lei da aliança e da interdição do incesto, apresentando-se, assim, como um discurso exemplar da costura dos dois dispositivos: o da aliança e o da sexualidade, operantes no século XIX (FOUCAULT, 1976, p.171).

Segundo Foucault, se durante mais de um século o Ocidente se interessou tanto pela interdição do incesto como ponto de passagem obrigatório para a cultura, é, talvez, uma maneira de se defender da extensão dos dispositivos da sexualidade emergentes, cujos inconvenientes eram os de relativizarem as leis e formas jurídicas da aliança baseadas na interdição do incesto. Nesse contexto, afirmar a interdição do incesto como lei universal é uma garantia de que esse dispositivo do sexo que começava a emergir não poderia escapar ao velho sistema de aliança.

Para Foucault, a teoria do sujeito e do desejo na psicanálise está ainda atrelada à hipótese repressiva e a uma concepção jurídica do poder, mesmo se de maneira mais sofisticada, na medida que, para a psicanálise, a lei que reprime a sexualidade incita igualmente o desejo. Como assinala Rajchaman, a psicanálise teria uma teoria do sujeito distinta de uma história de subjetivações, na qual subsistiria a concepção de um sujeito determinado por uma ordem simbólica universal a-histórica, no que se refere aos mitos universais fundadores do sujeito e da cultura. Em Freud, uma pré-história fictícia do primevo, reinterpretada por Lacan em termos de estrutura e da articulação primordial do desejo à lei (RAJCHMAN, 1994, p.125-126).

Deleuze e Guattari vão igualmente no anti-Édipo questionar, de forma contundente, a concepção psicanalítica do desejo atrelada à falta e à castração. A teoria fálico-edípica configura-se, no entender desses autores, como uma máquina de captura do desejo na medida que estaria "cassando a possibilidade de relacionamentos maquínicos do desejo com um devir outro que aquele determinado por seu discurso, impedindo assim a produção de desejo de experimentar de outros e positivos modos essa complexidade chamada inconsciente". Como aponta Orlandi, eles estariam realizando uma defesa ética e estética do inconsciente como um espaço social e político a ser conquistado, no sentido de sua expansão, como um lugar movente cuja maleabilidade é a dos limiares e fluxos que constituem a objetividade do próprio desejo enquanto um sistema aberto que quer sempre mais 
conexões e a partir do qual produzem-se fluxos de inconsciente num campo social e histórico (ORLANDI, 1995, p.185).

A partir desses questionamentos, cabe à psicanálise se interrogar em que medida a teoria da subjetivação e sexuação inconsciente determinada pela constelação representacional fálico-edípica pode ser considerada como um postulado universal ou se configuraria uma teoria de uma forma de subjetivação produzida numa determinada cultura. ${ }^{1}$

A tese de Freud, do binômio civilização-renúncia pulsional, como única forma de constituição do laço social, diria respeito a uma forma universal de cultura, ou seria a defesa de uma determinada concepção de cultura marcada pelo projeto iluminista-humanista do domínio da natureza pela razão, projeto esse tão brilhantemente questionado por Nietzsche e que, de há muito, vem revelando seus impasses? Birman (1999) e Arán (2002), ao situarem o debate cultura / civilização contemporâneo à época de Freud, vêm mostrar que a tese de Freud em O malestar da civilização não seria apenas uma defesa desse projeto, algumas de suas formulações deixando entrever sua inquietude face aos impasses de tal projeto.

Em trabalho recente, Arán (2000) aponta para a constituição de um campo teórico na psicanálise que, ao se interrogar sobre os limites do modelo fálicoedípico, "tenta pensar na teoria psicanalítica possibilidades de subjetivação tecidas pela singularidade que não obedecem a um modelo transcendente que se funda na exclusão do corpo". No seu entender, apesar da singularidade dos trabalhos de M. Schneider, M. David-Ménard e J. Birman, eles teriam alguns pontos em comum:

“1. uma crítica à centralidade da idéia do Édipo e da Castração na teoria psicanalítica, a qual se fundamenta no primado do falo e no recalque da feminilidade para os dois sexos; 2. uma releitura do conceito de corpo erógeno na teoria freudiana, com o objetivo de fundamentar metapsicologicamente a idéia de excesso pulsional considerada fundamental para pensar a experiência subjetiva; 3. a proposta de pensar a subjetivação a partir do modelo da estética, tendo como paradigma o texto 'Leonardo da Vinci', de 1910, em que Freud contrapõe a idéia de sublimação à de recalque.” (ARÁN, 2000, p.174-5)

Em que medida esse campo teórico, em sua crítica à centralidade do Édipo e da Castração, não estaria sobre os efeitos da crítica de Foucault e de Deleuze e Guattari a determinadas coordenadas representacionais universalizantes ainda presentes na psicanálise?

\footnotetext{
${ }^{1}$ Para uma análise crítica da teoria da diferença sexual na psicanálise ver os artigos de Arán, Nunes e Neri em Arán, 2002.
} 


\section{PSICANÁLISE E ANTI-ÉDIPO OU DA DELICADA TAREFA DE AGENCIAMENTOS INTENSIVOS}

Deleuze e Guattari, em O que é filosofia?, a propósito da noção de plano de pensabilidade, referem-se a agenciamentos de conceitos que se interligam em sua história, seu devir e suas conexões presentes (DELEUZE e GUATTARI, 1992, p.31).

Esse plano de agenciamento se opera na perspectiva de um pensamento em ruptura com a idéia de fundamento, de verdade universal. Em ruptura igualmente com a idéia de uma evolução gradual do conceito, na medida que, para a filosofia da diferença, a questão da verdade desloca-se para a problemática da diferença. Os conceitos, para esses autores, seriam como efeitos de atualização de um certo campo problemático, constituindo-se essencialmente de agenciamentos, sempre em vias de se fazer, desfazer, refazer (DELEUZE e GUATTARI, 1992). Assim, para Orlandi, ${ }^{2}$ agenciar é explorar conexões conceituais a partir de um campo problemático para tentar estabelecer encontros de corpos-conceitos, nos quais a diferença deve ser pensada não em termos de comparação, oposição, mas em termos de ressonâncias, faíscas.

Nessa perspectiva, o embate Anti-Édipo / Psicanálise ganharia, no nosso entender, ao ser explorado menos em termos de oposição, contradição e mais no plano de um agenciamento intensivo, de modo a estabelecer encontros desses corpos-conceitos que possam conduzir a um aumento de potência das respectivas obras. Sabemos, com Spinoza, que o encontro dos corpos pode levar a um aumento ou diminuição de potência, mas esse risco não deve nos impedir de tentar realizar esse trabalho.

Como revela Deleuze, numa entrevista concedida a l’Arc, o Anti-Édipo tem com a psicanálise uma interlocução privilegiada, não sendo demais lembrar que essa obra é ela mesma resultado do encontro de um filósofo com um psicanalista:

"Eu só trabalhava nos conceitos da psicanálise, e, ainda, timidamente. Guattari me falou daquilo a que já chamava as máquinas desejantes, toda uma concepção teórica e prática do inconsciente máquina, inconsciente esquizofrênico. Tive a impressão de que era ele que estava adiantado. Mas com o seu inconsciente-máquina, ele falava ainda em termos de estrutura, de significante, de phallus, etc. Era forçoso, visto dever tanto, a Lacan. Mas eu pensava que isso iria ainda melhor se encontrássemos os conceitos adequados (...) e renunciássemos a noções como estrutura, simbólico ou significante." (DELEUZE, 1972, p.47-48)

\footnotetext{
${ }^{2}$ Idéia desenvolvida no seminário "Como pensar os conceitos na filosofia da diferença”, PUCSP, 2002.
} 
Em entrevista concedida a Da Costa e Gondar (1995), Guattari fala da revolução extraordinária operada por Freud ao separar, com a noção de pulsão, a vida instintiva do homem da vida pulsional. A dimensão criadora da pulsão, em Freud, consistiria menos em uma separação radical com a vida instintiva e mais no sentido de uma crítica a certa concepção científica do instinto como fixo, que não contemplaria a complexidade dos processos vitais em suas formas, mesmo as mais elementares.

Para Guattari, o que interessa é muito menos a representação pulsional, pois esta perspectiva acaba dando à pulsão o estatuto de uma infra-estrutura biológica, e sim ligar a pulsão à existência, não à existência massiva, dada ontologicamente, mas como construção de existência, heterogênese dos componentes existenciais: "Para mim não há uma distinção entre inconsciente e pulsão, mas uma relação de imanência entre a pulsão e o inconsciente” (GUATTARI, apud Da Costa e Gondar 1995, p.102).

De um lado, essas afirmações deixam entrever a importância dos conceitos de inconsciente e de pulsão no horizonte da formulação do inconsciente maquínico do Anti-Édipo. De outro lado, a relação de imanência entre a pulsão e o inconsciente remete a uma problemática central da obra freudiana, a questão da articulação pulsão / representação, objeto de vivo debate e de diferentes interpretações na psicanálise.

Esses comentários de Deleuze e Guattari abrem um leque de interrogações que se colocam como pano de fundo da nossa tentativa de efetuar um agenciamento entre o conceito de pulsão da obra freudiana e a formulação de máquina desejante, que possibilite escutar novas ressonâncias: o embate do Anti-Édipo se dá com o texto freudiano ou com a leitura estruturalista proposta por Lacan? Em que medida poderíamos considerar as formulações de máquina desejante e corpo intensivo como "novas potências conceituais expressivas e interrogativas do texto freudiano" ? ${ }^{3}$ Os conceitos freudianos de pulsão e de corpo erógeno poderiam se agenciar em sua história e seu devir — com as formulações de máquina desejante e de corpo intensivo de Deleuze e Guattari? Quais os eventuais agenciamentos entre esses conceitos em suas diferenças? Em que medida é a potencialização de alguns conceitos da obra freudiana que permite a esses autores no Anti-Édipo se desvencilharem das noções de estrutura, simbólico e significante para pensar o inconsciente maquínico?

\section{PULSÃO / MÁQUINA DESEJANTE}

Como assinala Orlandi (1995), a nova maquinação conceitual do Anti-Édipo emerge como um questionamento ativo de duas linhas de reflexão que estariam se esgotando: 1) uma linha de curto alcance, a vertente estruturalista, que, fixandose no privilégio do simbólico, acaba promovendo o despotismo do significante;

\footnotetext{
${ }^{3}$ A expressão é de Orlandi.
} 
2) uma linha de longo alcance, na própria história do pensamento, para subverter os ancoradouros da representação, da identidade, libertando a diferença de sua clausura reflexiva para pensá-la como diferença pura, através do legado de Spinoza e Nietzsche, de modo a estabelecer a primazia ontológica da diferença: o ser se diz da própria diferença.

Nessa perspectiva, trata-se então de pensar novas formas de engendramento de processos de subjetivação, formular uma concepção imanente das sínteses do inconsciente, um produtivismo ou construtivismo do inconsciente, na medida que o inconsciente, atrelado à representação e ao significante, não bastava a Deleuze e Guattari pois encontrava-se incapaz de pensar o plural e o múltiplo. Trata-se de eliminar a redução do inconsciente ao problema da falta, para concebê-lo como uma lógica de fluxos, capaz de privilegiar o real e não o imaginário e o simbólico.

Nessa visão produtivista do inconsciente, cujo cerne está na introdução do conceito de produção no desejo e na posição deste como princípio imanente à produção, desclassificando a longa história das explicações do desejo pela falta, Deleuze e Guattari efetuariam "uma transposição do conceito de pulsão para o de máquina desejante”. As máquinas desejantes operando como “substitutos esquizoanalíticos das pulsões psicanalíticas no Anti-Édipo” (ORLANDI, 1995, p.179).

Esse comentário nos é valioso, pois, ao nosso ver, evidencia que o novo plano conceitual proposto por Deleuze e Guattari no Anti-Édipo não pode fazer a economia da formulação freudiana de pulsão.

A complexidade do conceito da pulsão na obra freudiana e "a teia nocional que emaranha o tema pulsão nos escritos de Deleuze e Guattari à demanda de um trabalho de quase decifração" (ORLANDI, 1995, p.149) já indicam quão árdua é a tarefa desse agenciamento pulsão / máquina desejante. Antes de avançar nessa tarefa, queremos assinalar alguns parâmetros que irão balizar nosso trabalho:

1. No que concerne à problemática pulsão / representação, nosso trabalho se inscreve em um campo teórico que privilegia, na metapsicologia freudiana, o conceito de pulsão para pensar o psiquismo inconsciente como um aparato pulsional que se constitui em uma rede de afetação pelo outro, em contraponto a uma outra perspectiva que, ao privilegiar a representação inconsciente, concebe o psiquismo como um aparato de captura e inscrição da força pulsional na representação e na linguagem.

2. Considerando a obra freudiana como um texto atravessado pela lógica do paradoxo, que aponta para vários sentidos, caminhando em direções opostas ao mesmo tempo, destacamos a tensão discursiva que se faz presente ao longo de sua obra. Schneider assinala a existência de um texto e de um subtexto no discurso freudiano, o que torna possível a coexistência, num mesmo texto ou num determinado momento de sua obra, de linhas conceituais que privilegiam o campo da intensidade pulsional ao lado de outras que privilegiam o campo da representação. 
Essa perspectiva nos leva a valorar em diferentes momentos da obra freudiana formulações ou conceitos que no nosso entender possibilitam pensar os destinos da subjetivação e da sexuação na psicanálise fora do determinismo da constelação representacional universal fálico-edípica.

A partir do campo problemático da pulsão, nos propomos a sugerir a possibilidade de eventuais conexões conceituais entre as formulações freudianas do aparato psíquico no Projeto (1895), da pulsão parcial e de corpo erógeno (1905), da pulsão de morte e do conflito pulsional Eros / Tânatos (1920) e a formulação de máquina desejante do Anti-Édipo. Nessa tentativa de agenciamento inicial, nosso interesse é pensar em que medida o trabalho interrogativo sobre os conceitos freudianos de pulsão sexual parcial, corpo erógeno e pulsão de morte, liberando novas potências conceituais, permitem a Deleuze e Guattari se desvencilharem das noções de estrutura, significante e simbólico para pensarem o inconsciente maquínico e o corpo sem órgãos no Anti-Édipo.

\section{ANTI-ÉDIPO: MÁQUINA DESEJANTE, LÓGICA DE FLUXO}

O projeto do Anti-Édipo é pensar o inconsciente não como um teatro de representação e sim como uma fábrica, uma máquina para produzir, eliminando a redução do desejo ao problema da falta e da representação para pensá-lo como uma lógica de fluxos: "Isto funciona em toda parte, às vezes sem parar, às vezes descontínuo. Isto respira, esquenta, come (...). Em toda parte são máquinas, de maneira alguma metaforicamente, máquinas de máquinas, com seus acoplamentos, suas conexões (...) Somos todos bricoleurs, cada um suas pequenas máquinas” (DELEUZE e GUATTARI, 1976, p.15).

Nessa concepção, o inconsciente produtivo é formulado como uma máquina desejante de agenciamento contínuo de fluxos e cortes (seio-boca), uma máquina órgão para uma máquina energia, que não cessa de efetuar o acoplamento de fluxos contínuos e de objetos parciais fragmentados:

“Em toda parte são máquinas com seus acoplamentos e conexões. Uma máquina órgão para uma máquina energia, sempre fluxos e cortes. Há sempre uma máquina produtora de um fluxo e uma outra que lhe é ligada, operando um corte, na extração de fluxo (o seio - a boca). E como a primeira é por sua vez ligada a uma outra, em relação à qual ela se comporta como corte ou extração, a série binária é linear em todas as direções. O desejo não cessa de efetuar acoplamentos de fluxos contínuos e de objetos parciais, essencialmente fragmentários e fragmentados. O desejo faz escorrer, escorre e corta. Fluxo de babas, esperma, urina, que são produzidos por objetos parciais, constantemente cortados por outros objetos parciais, os quais produzem outros fluxos, recortados por outros objetos parciais." (DELEUZE e GUATTARI, 1976, p.20) 


\section{PROJETO PARA UMA PSICOLOGIA CIENTÍFICA: O APARELHO PSÍQUICO COMO UM APARATO DE AGENCIAMENTO DE FLUXOS}

O Projeto para uma psicologia científica (1895) é o primeiro modelo do psiquismo humano formulada por Freud. Destacando o ponto de vista da circulação de quantidades de energia, ele apresenta o aparelho psíquico como resultante de um processamento de quantidades de excitação que lhe atravessam. Como aponta Ménard, não se trata de um aparelho energético organicista nem de um aparelho mental, mas de um aparelho de prazer, desprazer e angústia, que visa a obtenção de uma satisfação, o prazer sendo equivalente para Freud de uma descarga energética. Nessa ótica, a diferença entre a realização do prazer e ato de pensar seria da ordem de níveis distintos de repartição e graduação da energia, o pensamento sendo um prazer adiado (DAVID-MÉNARD, 1983, p.10).

Como assinala M. Cavalcanti (2000), esse aparelho psíquico se constitui face a duas exterioridades: 1) uma periferia interna — a pressão de fontes corporais que gotejam permanentemente quantidades, exigindo um trabalho de processamento dessa intensidade; 2) uma periferia externa — as imagens de sensações captadas do mundo exterior. Segundo Freud, uma percepção só deixa marcas quando participa de uma experiência de satisfação ou de dor. O sistema Psi vai se constituir no momento em que as duas exterioridades se encontrarem e se ligarem pela experiência de satisfação. O sistema Psi vai, então, registrar, no lugar da pressão desprazerosa, traços pontuais que não se constituem como uma cadeia e não são equivalentes à representação inconsciente.

Esses primeiros traços são marcas de prazer, signos de percepção auditivos, gustativos, táteis e visuais, que podem ser potencialmente alucináveis: quando a pressão da periferia interna volta a crescer, a criança alucina a presença do seio, sem que o objeto real esteja presente no mundo externo, produzindo uma percepção alucinatória pela presentificação desses signos de percepção. A alucinação do seio se apresenta como uma produção inaugural do inconsciente, que promove uma primeira inscrição de signos inconscientes tal como formulado por Freud, no esquema de memória da carta 52 a Fliess.

Estamos diante de um psiquismo que se constitui como um circuito pulsional de processamento de intensidades, visando a obtenção do prazer que só se dá num encontro com o outro, que vai deixar marcas eróticas singulares das experiências de dor e satisfação. A subjetivação apresenta-se como uma produção imprevisível, indeterminada, no sentido de produções singulares e abertas.

Na experiência de alucinação do seio, os traços das experiências de satisfação que a criança inscreve já são diferenciados: é a maneira como ela cheirou, tocou, degustou, que vai marcá-la de forma singular, abrindo-a para novas experiências que produzirão outras marcas, a subjetivação podendo ser vista como uma proliferação de experiências singulares. 
A subjetivação não precisa, então, ser pensada em relação à falta, como ausência de satisfação que vai produzir representação — o desejo como resultante da insatisfação. Nem, tampouco, como recalque de uma experiência mítica fundante - o gozo absoluto de ser o falo da mãe. A experiência de satisfação não é mítica, ela é real, parcial, instaurando um circuito pulsional de produção de diferença.

Em que medida podemos agenciar em sua história e suas conexões presentes esses dois aparatos de fluxos formulados no Anti-Édipo e no Projeto?

\section{PULSÃO PARCIAL / MÁQUINA DESEJANTE}

No Projeto, a pulsão é definida como uma pressão interna da qual o organismo não pode escapar, o psiquismo se constituindo como um circuito pulsional que visa dar um destino a essa pressão que exige satisfação. Em função do desamparo da criança, esse circuito só pode se constituir na relação com o outro e é a partir dessa primeira experiência de prazer, parcial, fragmentária, de acoplamento da boca do bebê com o seio, que se inaugura um primeiro circuito de satisfação, circunscrevendo uma pulsão parcial em torno de uma primeira zona erógena oral.

O conceito de pulsão sexual parcial e de zona erógena será retomado por Freud nos Três ensaios sobre a sexualidade (1905) ao enunciar a sexualidade humana como disruptiva em relação ao instinto predeterminado e a diferença anatômica, estabelecendo uma diferença entre instinto e pulsão. Como afirma Freud, é o estudo das manifestações sexuais infantis que vão revelar os traços essenciais da pulsão: ela não tem objeto sexual determinado, está sob o domínio de zonas erógenas eletivas, qualquer parte do corpo podendo ser investida pela pulsão. A sexualidade infantil aponta para a plasticidade da pulsão sexual perverso-polimorfa que se caracteriza por pulsões parciais, as zonas erógenas sendo fontes de diferentes pulsões parciais.

Embora a formulação da pulsão sexual parcial esteja inserida no contexto da primeira tópica e do primeiro conflito pulsional que, segundo Birman (1996), encerra uma aposta na captura da pulsão pela representação, configura-se como um conceito revelador da plasticidade pulsional na constituição da sexualidade e do psiquismo humano. Queremos sublinhar a radicalidade do conceito de pulsão sexual perverso-polimorfa na obra freudiana para evidenciar que ele é um referencial que permite ao discurso psicanalítico romper com o discurso essencialista sobre a diferença sexual, colocando por terra qualquer possibilidade de satisfação e complementaridade na sexualidade humana, sem ter que recorrer ao determinismo simbólico fálico (cf. NERI, 1999, cap. IV). Os trabalhos de Schneider, DavidMénard e Birman retomam a potencialidade da formulação freudiana de corpo erógeno, valorizando respectivamente: a teoria da sedução, o corpo erógeno da histeria como presentificação da pulsão, o Eu real originário e o masoquismo erógeno. 
Deleuze e Guattari, em sua crítica à concepção psicanalítica do desejo atrelada ao Édipo e à castração, formulam o inconsciente como um máquina de agenciamento de fluxos na qual o desejo não cessa de efetuar acoplamentos de fluxos contínuos e objetos parciais. Como assinala Orlandi, ao pensarem o inconsciente produtivo como resultantes de heterocomposições, as pulsões parciais são repensadas no Anti-Édipo como peças de máquinas desejantes (ORLANDI, 1995, p.160).

No Anti-Édipo as pulsões parciais serão pensadas como impulsões funcionando em mecanismos que decidem sobre sua posição e destinação: não há uma evolução das pulsões parciais que as faria progredir, com seus objetos, para um todo de integração, assim como não há totalidade primitiva da qual derivaria:

“As máquinas desejantes só são atingidas a partir de um certo limiar de dispersão que não deixa subsistir nem sua identidade imaginária, nem sua unidade estrutural (essas instâncias são ainda da ordem da interpretação, isto é, da ordem do significado ou do significante). As máquinas desejantes têm como peças os objetos parciais que definem as working machines, mas num estado de dispersão tal que uma peça não cessa de remeter a uma peça de uma máquina totalmente diferente. Não nos apressemos em introduzir um termo que seria como um falus estruturando o conjunto, unificando e totalizando. Em toda parte há libido e nenhuma peça das diferentes máquinas tem o privilégio de ser um falus (...) Toda essa concepção é uma idéia que a razão impõe ao inconsciente e que ela introduz na esfera pulsional (...) É aí que o desejo se vê preso numa armadilha, num conjunto molar unificado e identificado. Mas as máquinas desejantes vivem, ao contrário, sob o regime de dispersão dos elementos moleculares." (DELEUZE E GUATTARI, 1976, p.409)

No Anti-Édipo, Deleuze e Guattari vão igualmente valorizar a formulação de corpo erógeno:

"É nesse sentido que Serge Leclaire chamava corpo erógeno não a um organismo despedaçado, mas a uma emissão de singularidades pré-individuais, uma pura multiplicidade dispersa e anárquica, sem unidade nem totalidade (...) Se batermos indefinidamente no mesmo conjunto de puras singularidades, podemos pensar que nos aproximamos da singularidade do desejo do sujeito. É claro que podemos sempre instaurar ou restaurar um laço qualquer entre esses elementos (...) remetendo-os a um organismo que funcionaria fantasmaticamente como unidade perdida ou totalidade por vir. Mas não é sob esse aspecto que os objetos parciais são elementos do inconsciente (...). Sua dispersão não tem nada a ver com uma falta e constitui seu modo de presença na multiplicidade que formam sem unificação nem totalização." (DELEUZE e GUATTARI, 1976, p.411) 
Como aponta Orlandi, bem antes do Anti-Édipo, na Apresentação de Sacher-Masoch (1967), Deleuze instaura uma discussão com o conceito freudiano de pulsão parcial.

Partindo da formulação de Freud do par de opostos sadismo-masoquismo, que afirma: 1) a reversibilidade do lado ativo e passivo da perversão de tal modo que um sádico é ao mesmo tempo um masoquista; 2) a identidade de experiência visto que o ter vivido a experiência do prazer com dor seria o que levaria o sádico a ter prazer em causar dor; 3 ) a transformação das pulsões sexuais num intercâmbio em que umas acabariam passando para as outras, Deleuze pretende realizar uma crítica a essa unidade semiótica presente na formulação freudiana de sadomasoquismo. Ele propõe concebê-las como unidades semiológicas distintas, pois no seu entender a unidade sado-masoquismo conduz a um uso da teoria das pulsões parciais que procura apagar as diferenças.

O que nos interessa destacar é a crítica de Deleuze ao uso da teoria das pulsões parciais dentro da perspectiva de conduzir seja a uma unidade, seja a uma síntese totalizadora, dentro de uma visão de evolução da pulsão parcial à genitalidade, seja a uma oposição dialética reducionista que conduz aos pares opostos sádico ativo viril / masoquista passivo feminino.

Como assinala Orlandi, a insistência de Deleuze na especificidade de uma semiologia distinta entre o sadismo e o masoquismo como "figuras completas" e não parciais, que incorreriam na redução do múltiplo, vai de par, nessa mesma obra, com a afirmação da positividade da noção de pulsão parcial, desde que inserida na concretude diferencial de cada uma dessa figuras completas (ORLANDI, 1995, p.162).

Queremos apontar para a presença do conceito de pulsão sexual parcial no horizonte da formulação de máquinas desejantes como “a imersão das pulsões em multiplicidades substantivas". No entanto, se a plasticidade da pulsão sexual perverso-polimorfa se apresenta como plano de pensabilidade da formulação das máquinas desejantes, a leitura da esquizoanálise potencializa a radicalidade desse conceito freudiano que permite pensar a plasticidade da sexualidade humana em ruptura com o determinismo anatômico, sem ter que recorrer a um determinismo simbólico universal. Como indaga Schneider (2000), ao questionar os limites do modelo fálico-edípico, para pensar a diferença sexual na teoria psicanalítica: O que se ganhou ao se substituir o determinismo anatômico do discurso científico pelo determinismo universal fálico?

\section{PULSÃO DE MORTE / MÁQUINA DESEJANTE}

A problemática da pulsão / representação se apresenta talvez como a questão mais complexa da obra freudiana, nos colocando face a uma exigência permanente de trabalho. Como mostra Birman (1996), se a questão da intensidade pulsional e do 
afeto estava presente no início da obra freudiana, pouco a pouco, o aspecto qualitativo, a representação, ganha o centro da cena e é a partir de 1915 que o excesso pulsional retorna como questão. Em 1920, Freud formula a pulsão de morte sem representação, o último conflito pulsional pulsão de vida / pulsão de morte vem assinalar os limites do sujeito da representação inconsciente regido pelo princípio do prazer, tal como formulados na primeira tópica e na primeira teoria pulsional, em sua aposta na captura da força pulsional pela representação. É esse sujeito da representação inconsciente, determinado pelo simbólico, que agora cai por terra.

Em outro trabalho (NERI, 1999, cap. V), nos propusemos a pensar a pulsão como "um campo de forças, de trabalho e de ação", a partir das definições de Freud da pulsão como “conceito limite entre o anímico e o somático” e como “fragmento de atividade”, tal como formuladas em A pulsão e seus destinos. Uma possível leitura bem difundida é a de que o trabalho exigido pela pulsão seria o de simbolização. No entanto, essa perspectiva acaba reeditando uma dicotomia pulsão $=$ força versus psíquico = representação.

Ao apresentarmos a pulsão como um campo de forças e de trabalho em ação, tentamos pensar o trabalho psíquico em termos de deslocamento e dispêndio de energia, a diferença entre pensar e gozar marcada por níveis diferentes de repartição de energia e não apenas em termos de diferença qualitativa. As relações entre o gozo e o pensamento são assim de proximidade, de graduação e intensidade e não uma diferença qualitativa. Se a pulsão impele ao trabalho psíquico, ela é também psíquica (está na fronteira entre o psíquico e o somático), o circuito por ela ordenado de remanejamentos e dispêndios energéticos, podendo então ser considerado um trabalho do psiquismo. Em sua formulação sobre o trauma em Para além do princípio do prazer, Freud vai enunciar, justamente, uma ligação prévia a instauração do princípio de prazer. Frente à inundação energética, há uma tarefa anterior à instauração do princípio do prazer: dominar a excitação, tentando ligar psiquicamente a quantidade de energia que irrompeu de forma violenta, apontando para uma ligação no campo da intensidade que age independente do campo da representação e do princípio do prazer.

A leitura que propomos do último conflito pulsional freudiano Eros /Tânatos tal como formulado por Freud em Para além do princípio do prazer é de concebê-lo não em termos de uma oposição dialética pulsão de vida $=$ erotismo $=$ simbolização $=$ ordem versus Tânatos = força pulsional mortífera $=$ caos, que veria Eros como uma síntese-superação da contradição, mas em termos de um combate de forças e de uma mescla pulsional.

Nessa perspectiva, a formulação desse dualismo nos leva a reafirmarmos nossa idéia da pulsão como um campo de forças, quando uma força interfere com a outra, instaurando um combate de forças e não um conflito a ser superado. Com efeito, esse combate de forças vai produzindo diferenças, graduações intensivas 
que se convertem ora na dominação da pulsão de vida, ora na hegemonia da pulsão de morte, sem que o domínio de uma força jamais anule a força da outra ou represente a superação de uma força pela outra. Tanto na criação como na destruição, trata-se de uma mescla de forças.

Frente ao que nos pareceu um duplo aspecto da pulsão de morte formulada por Freud nesse texto, optamos por não dar prioridade a uma vertente, destacando as duas dimensões apresentadas, acreditando que elas possam ser portadoras da própria complexidade da pulsão: 1) a dimensão conservadora da pulsão de morte que, regida pelo princípio de Nirvana, busca uma eliminação total de tensão desejando um retorno ao inanimado; 2) a dimensão criadora de uma força indomável que está permanentemente pressionando o psiquismo a trabalhar, força disruptiva que impele à mudança, rompendo as ligações com Eros, que visariam uma síntese paralisante.

A idéia de uma oposição de forças como combate aponta para esse dualismo como um paradoxo. Assim, segundo Freud, se Eros como força vital avança para a frente promovendo ligações desse excesso, Eros, quando quer ligar, também recua para trás, buscando a união perdida, tal como enunciada no mito do andrógino. As ligações cada vez maiores de Eros tendem a um equilíbrio homeostático que é paralisante. QuandoTânatos desintegra as ligações, ele está, por um lado, querendo a descarga total e ausência de tensão, mas está, também, empurrando o organismo para a frente, pois ao desintegrar abre possibilidade de novas ligações, de mudança. Atravessada por esse campo de forças, numa acrobacia entre a vida e a morte, a subjetivação se processa como um devir singular desse combate-mescla de forças.

Nessa leitura que pretende destacar a dimensão criadora da pulsão de morte, queremos ainda assinalar os seguintes aspectos: 1) A própria natureza conservadora da pulsão de morte enquanto retorno ao inanimado é correlata da constatação de que os processos vitais implicam em tensão. 2) A pulsão de morte vem se contrapor a uma perspectiva evolucionista que supõe que o homem caminha em direção ao progresso, apontando para uma imprevisibilidade do circuito pulsional. 3) A formulação da pulsão de morte como força demoníaca mostra que os processos vitais não são da ordem da autopreservação e sim da afirmação de forças, o mais-além-do-princípio-do-prazer, deslocando o psiquismo do pólo homeostático do evitamento de desprazer para o pólo de produção de intensidades, em que tanto o prazer como o desprazer são da ordem da intensidade.

Como indica Orlandi, é ainda no texto Sacher-Masoch que Deleuze começa uma interlocução teórica com o conceito freudiano de pulsão de morte. Limitamo-nos nesse trabalho a abordar essa interlocução inicial assinalando, contudo, que a problemática da pulsão de morte no pensamento de Deleuze terá posteriormente desdobramentos fundamentais em Diferença e repetição e no Mil platôs. Nosso objetivo é 
igualmente o de sublinhar a presença desse conceito freudiano no horizonte da formulação do inconsciente maquínico, em contraponto a um inconsciente estrutural, destacando sua importância para a formulação do corpo sem órgãos no Anti-Édipo.

Considerando o texto Para além do princípio do prazer uma obra-prima na qual "Freud atinge a genialidade de uma reflexão propriamente filosófica”, Deleuze vai valorizar a formulação freudiana da pulsão de morte como esse além irredutível ao princípio do prazer. Embora reine sobre tudo, o princípio de prazer não governa tudo, pois ele deixa escapar um resíduo irredutível a ele. Mais ainda: não se deve entender esse resíduo como contrário, mas como exterior e heterogêneo em relação ao princípio do prazer. Deleuze, ao fazer uma leitura da última teoria pulsional Eros / Tânatos, introduz uma distinção entre instinto e pulsão. São denominados instintos, precisamente, os princípios em sua transcendentalidade: Eros, fundamento do princípio empírico do prazer e Tânatos, o sem-fundo, no qual emerge Eros.

Sendo princípios transcendentais, eles só aparecem na experiência como combinação dos dois, quando se revela o papel de Eros de "ligar a energia de Tânatos". Ora, se na experiência Eros se faz ouvir e age, Tânatos, o sem-fundo trazido à superfície por Eros, é essencialmente silencioso. É a esta instância transcendental e silenciosa que Deleuze reserva estritamente o termo instinto, instinto de morte. O que seriam então as pulsões para Deleuze? Os representantes diretos de Eros e os representantes indiretos de Tânatos, sempre misturados no Id. Ou seja, as pulsões eróticas e destrutivas seriam os componentes de combinações determinadas. Portanto, no limite, Deleuze pode dizer que Tânatos, o silencioso instinto de morte simplesmente "é" (ORLANDI, 1995 p.165, 169).

Abrem-se assim, segundo Orlandi, as possibilidades: 1) de apresentar as produções do desejo como o inverso de uma construção configurada numa estrutura que se ordenaria em torno do recalque para concebê-la como uma proliferação de mesclas pulsionais de Eros eTânatos; 2) de eliminar o "não" no inconsciente, dado que a pulsão que o representa indiretamente é "sempre dada no inconsciente" como "o inverso de uma construção", tratando-se, portanto de uma pulsão, "que se combina necessariamente com a libido, esta energia de Eros”.

A formulação no Anti-Édipo do inconsciente produtivo como máquina desejante de agenciamento contínuo de fluxos e de cortes está de algum modo referida a essa leitura das pulsões como componentes heterogêneos resultantes da mescla pulsional de Eros e Tânatos.

Após apresentarem as máquina desejantes como agenciamento contínuo de fluxos e cortes, eis que Deleuze e Guattari nos introduzem à noção do corpo sem órgãos. Como eles mostram, nas máquinas desejantes os fluxos de energia estão ainda muito atados, os objetos parciais ainda muito orgânicos. Há um produzir, um produto, uma identidade produto-produzir. É essa identidade que forma um 
terceiro termo na série linear: enorme objeto não diferenciado. Tudo para.Tudo se coagula. Depois tudo vai recomeçar (DELEUZE e GUATTARI, 1976, p. 23).

"Um puro fluido em estado de liberdade sem corte deslizando sobre um corpo pleno. Nem boca, nem língua, nem dente. O corpo sem órgãos, um puro fluído indiferenciado, uma vibrátil indeterminação, mas que pressupõe a produtividade das máquinas desejantes, agenciando fluxos e cortes. O corpo pleno sem órgãos é o improdutivo, o iningendrado. Instinto de morte eis o seu nome. Porque o desejo deseja também isso à morte, porque o corpo pleno da morte é seu motor imóvel, como deseja a vida, porque os órgãos da vida são a working machine. As máquinas desejantes só andam desarranjadas, desarranjando-se sem cessar. O corpo sem órgãos é o improdutivo mas perpetuamente reinjetado na produção. Ele é antiprodução mas é ainda uma característica da síntese conectiva ou produtiva, acoplar a produção a um elemento da antiprodução (DELEUZE e GUATTARI 1976, p.23)

Estamos aqui buscando possíveis ressonâncias entre a articulação das máquinas desejantes / corpo sem órgãos, tal como formulados no Anti-Édipo, com a leitura que propomos da última teoria pulsional pulsão de vida / pulsão de morte, tal como enunciadas por Freud em Para além do princípio do prazer. Em que medida podemos agenciar máquina desejante / corpo sem órgãos com a última teoria pulsional pulsão de vida / pulsão de morte concebidas como combate de forças ou mescla pulsional, que resultariam em combinações determinadas de Eros / Tânatos.

Como procuramos mostrar, nos parece que tanto em Para além do princípio do prazer como no Anti-Édipo, trata-se de pensar as produções desejantes do inconsciente no campo das intensidade dos fluxos pulsionais. De um lado, Eros / máquina desejante promove acoplamentos dos fluxos. De outro lado, Tânatos / corpo sem órgãos, ao quebrar as ligações, impede que Eros / máquina desejante realize sínteses cada vez maiores, funcionando como força disruptiva que possibilita a criação de novas ligações.

Em que medida podemos agenciar corpo sem órgãos / Tânatos como expressão do duplo aspecto da pulsão de morte:

1. A dimensão da pulsão de morte que busca na eliminação total da descarga um retorno ao inanimado tal como formulada pelo Freud em Para além do princípio do prazer parece-nos estar em conexão conceitual com a formulação do corpo sem órgãos no Anti-Édipo como "puro fluido indiferenciado, o improdutivo, o iningendrado". "Instinto de morte é o seu nome. Por que o desejo deseja também isso, a morte."

2. A dimensão criadora da pulsão de morte enquanto força indomável que pressiona o psiquismo a trabalhar, força disruptiva que impele à mudança, pode- 
ria estar agenciada com a formulação do corpo sem órgãos enquanto vibrátil indeterminação que pressupõe a produtividade das máquinas desejantes, agenciando fluxos e cortes. Igualmente, a formulação de Tânatos como vindo romper as ligações de Eros que, segundo Freud, visariam sínteses paralisantes, nos parece em consonância com a formulação do corpo sem órgãos como vindo desatar os fluxos de energia que estariam ainda muito atados nas máquinas desejantes, pois ao desfusionar esses acoplamentos, possibilita novos agenciamentos da máquina desejante.

Buscamos aqui mostrar que as formulações de Tânatos / corpo sem órgãos assinalam o duplo aspecto de impulso destruidor e renovador. Como sublinha Fortes (2000), a face da transformação e da criação se alimenta do aspecto dispersivo, disruptivo e fragmentário da pulsão de morte. Ao não terem o seu poder nas sínteses características de Eros / máquina desejante, Tânatos/ corpo sem órgãos encontram, na própria dispersão, a saída vital frente às forças aniquilantes que também o constituem. Quando a pulsão de morte desintegra as sínteses, constituindo-se como puro fluido que busca a descarga, ela empurra também a máquina desejante para novas transformações. Como mostram Deleuze e Guattari, as máquinas desejantes só andam desarranjadas, desarranjando-se sem cessar. O corpo sem órgãos é o improdutivo mas perpetuamente reinjetado na produção, pois é uma característica da síntese conectiva ou produtiva acoplar a produção a um elemento da antiprodução.

Por fim, pretendemos assinalar uma possível conexão conceitual entre a formulação de corpo sem órgãos e a formulação freudiana do masoquismo erógeno em O problema econômico do masoquismo (1924) como uma mescla pulsional Eros / Tânatos, como nos diz Freud: "uma primeira ligação de Eros com a pulsão de morte”. O masoquismo erógeno nesse momento da obra freudiana, que privilegia o registro da intensidade, apresenta-se como um desdobramento do conceito de corpo erógeno formulado no contexto da primeira tópica, enquanto um primeiro circuito pulsional inaugurado pela experiência de satisfação.

\section{O CORPO ERÓGENO DA HISTERIA / O CORPO SEM ÓRGÃOS}

Orlandi, no texto "Corporeidades em minidesfiles" (2002), propõe um plano de ordenação de grandes linhas de interrogação sobre o corpo no pensamento ocidental:

1. O corpo é pensado como conjunto de funções e órgãos pelo discurso filosófico e científico;

2. O corpo é pensado como mero instrumento da alma em Platão e Aristóteles. E, ainda que Descartes, ao pensar o corpo e a alma como substâncias distintas, relativiza essa tese, seu dualismo acaba garantindo sob novas bases a supremacia da alma e a instrumentalização do corpo; 
3. É com Espinoza e Nietzsche que se alcança a espessura conceitual do corpo no campo filosófico. Para Espinoza, trata-se de pensar a potência dos corpos de afetarem e serem afetados: "Até o presente, ninguém determinou o que pode um corpo". Para Nietzsche, "o corpo é uma grande razão e a alma é somente uma palavra para alguma coisa do corpo."

Advindo o corpo como questão que se impõe ao pensamento, há pelo menos, segundo Orlandi, três linhas filosóficas de indagação sobre o corpo na contemporaneidade:

1. A experiência fenomenológica do "corpo próprio" (Merleau-Ponty) que pensa o corpo próprio como uma operação reflexiva que "exprime uma certa maneira de existir antes de uma certa maneira de pensar" ou em termos de "uma modulação de existência, um nó de significações vivas" e que vem se opor a que se tome o corpo como mero objeto do pensamento;

2. O corpo em meio a saberes e poderes (Foucault): trata-se de perguntar sobre as práticas discursivas e não discursivas que se investem sobre os corpos, buscar uma ontologia histórica de nós mesmos, que se interessa pelas condições concretas que nos constituem. O que estamos ajudando a fazer de nós mesmos, em meio à redes de saberes e poderes, que ao mesmo tempo nos constituem?

3. O corpo sem órgãos (DELEUZE e GUATTARI). A partir da formulação de Artaud, esses autores vão no Anti-Édipo conectar o corpo sem órgãos a uma complexa pragmática do desejo. Trata-se de combater o desejo ligado à falta, reunindo o desejo com o corpo sem órgãos, para mostrar o que se processa no encontro entre corpos. O corpo sem órgãos como um contínuo circuito de intensidades marca a estranheza do plano de imanência do corpo sem órgãos em relação ao corpo orgânico.

Por que não incluir a psicanálise nesse minidesfile da corporeidade como uma das linhas de interrogação que colocam o corpo como questão? Se concordamos com a afirmação de Orlandi de que o pensamento de Espinoza e o de Nietszche produz um grande susto na prepotência das almas, entendemos que a psicanálise se configura, na passagem do século XIX ao XX, como responsável igualmente por um grande abalo na prepotência da racionalidade filosófica e científica dominante nesse momento.

Queremos sublinhar que o descentramento do sujeito da razão operado pela psicanálise, ao deslocar o sujeito da consciência para o inconsciente, realiza-se em torno da interrogação sobre o corpo da histeria ao dar crédito e sentido a esse corpo que desafia o corpo anatômico da ciência e questiona a dicotomia corpo-espírito da tradição filosófica (cf. NERI, 2003). Revelando uma economia subjetiva corpórea, o corpo erógeno da histeria aponta, na cena inaugural da psicanálise, para uma subjetivação no registro da intensidade pulsional. Segundo a bela expressão de Swain (1986) "o corpo da histeria como teatro de transformação do pensamento". 
Como mostra Ménard (1983), a psicanálise se inaugura associando, de maneira complexa mas constante, a descoberta do inconsciente à descoberta do corpo erógeno pelo viés da crise histérica: 1) Os sintomas histéricos se expressam no corpo, corpo cujo estatuto resta precisar; 2) O psiquismo humano é concebido por Freud no Projeto (1895) como um aparelho de processamento de prazer, desprazer e angústia, em contraponto a uma concepção do psiquismo como um aparelho neurológico, orgânico, ou como um aparelho de representação, de memória, de linguagem.

“A expressão aparelho psíquico é ambígua pois este aparelho é um aparelho material que visa o prazer, e é preferível não falar de corporal ou psíquico para sublinhar a formulação freudiana que nunca se modificou: a sensação de prazer corresponde a uma descarga energética e motora." (DAVID-MÉNARD, 1983, p.9)

No entender da autora, não se pode subtrair a essa questão, sob pena de limitar a contribuição da psicanálise, seja reduzindo este conceito ao corpo biológico, ou colocando, como Lacan, que não há autonomia do pulsional em relação ao modo de constituição de um sujeito falante no lugar do Outro, operação pela qual se subsume a pulsão ao campo representacional, deixando de fora a dimensão da força pulsional e do afeto (idem, p.7).

Segundo a mesma autora, no texto Considerações sobre o ataque histérico, de 1909, a definição de Freud da crise da histeria "como fantasias traduzidas em linguagem motora, projetadas sobre a motilidade e figuradas como pantomima”, aponta para o fato de que, mesmo se a histeria é referida a um teatro da representação inconsciente, a idéia da representação não está ligada a uma representação mental mas a um teatro do corpo. A experiência plástica do gozo na histeria remeteria mais à dimensão da presentificação (darstellung), em oposição à da representação (vorstellung), muito mais ligada à filosofia enquanto representação mental consciente ou mesmo à lingüística estrutural na qual a representação inconsciente está ligada a uma depuração do afeto pela linguagem. Como assinala Schneider (1992), no fascínio pela razão estrutural, trata-se não só para Lacan de priorizar a linguagem nas formações do inconsciente, mas de reduzir a linguagem à lingüística estrutural, colocando como da ordem da natureza e do infra-humano o que não pode ser articulado em termos de uma oposição de significantes verbais, como a linguagem do sopro e do grito.

No nosso entender, a singularidade maior da psicanálise residiria na tentativa de pensar, pelo viés da histeria, uma subjetivação fora da dicotomia corpo-espírito, ser e pensamento, problematizando essa articulação de maneira inovadora. No entanto, o discurso psicanalítico acabou privilegiando a interpretação da histeria como teatro da representação inconsciente recalcada. 
Aprofundando a relação da histeria com o corpo, David-Ménard formula a noção de atualidade da pulsão, reportando-se à definição de Freud na carta 52 a Fliess: "Um ataque histérico não se constitui somente como uma descarga, mas como uma ação que conserva a caratecrística inerente de toda ação: ser um modo de se obter prazer."

Para Ménard o ataque histérico se configura não como uma representação do desejo inconsciente e sim como uma atualização do erotismo com o próprio corpo: o histérico coloca o objeto do seu desejo como se ele estivesse lá. Nessa atualização, coexiste a dimensão do movimento — da motricidade — e de um prazer presentificado. No entanto, ao mesmo tempo que a histeria presentifica com o corpo erógeno seu desejo (uma forma auto-erótica de realizá-lo), a crise histérica é também um apelo, uma cena endereçada ao outro, a reivindicação de uma presença do objeto do seu desejo, apontando para a dimensão da alteridade. A histeria se apresentaria como a figura maior de uma subjetivação que se opera na atualização da pulsão e na alteridade, uma subjetivação que se constitui num circuito pulsional de atravessamento pelo outro.

Em que medida, para se desvencilhar de um plano do corpo ainda contaminado pela imagem e representação, foi necessário a Deleuze e Guattari no Anti-Édipo tomar uma linha de fuga em relação ao corpo erógeno da histeria, privilegiando a formulação do corpo sem órgãos de Artaud, para pensar o corpo intensivo? Talvez não seja por acaso que somente num texto bem posterior Deleuze apresente uma ressonância entre o corpo sem órgãos e o corpo da histeria.

Essa ressonância que me é cara está presente em Lógica da sensação (1984) no qual, no capítulo intitulado “Histeria” Deleuze associa o corpo sem órgãos de Artaud ao corpo da histeria: "Há muitas aproximação ambíguas na vida, do corpo sem órgãos, o álcool, a droga, a esquizofrenia (...) mas a realidade viva deste corpo podemos nomeá-la de histeria e em que sentido?” (DELEUZE, 1984, p.34).

“Uma onda de amplitude variável percorre o corpo sem órgãos, traçando limiares e níveis segundo as variações de sua amplitude. Ao encontro da onda e das forças exteriores, uma sensação aparece. Um órgão será assim determinado por este encontro, mas um órgão provisório que só permanece durante a passagem dessa onda e a ação dessa força e que vai se deslocar para outro lugar. Os órgãos perdem assim qualquer constância no que concerne à sua localização ou sua função, os órgãos sexuais aparecem em toda parte. Com efeito, ao corpo sem órgão não faltam órgãos, o que lhe falta é o organismo, isto é, essa organização de órgãos. O corpo sem órgãos se define, então, por um órgão indeterminado, enquanto o organismo se define por órgãos determinados (...) O que é boca em um nível de encontro da força com o corpo pode se tornar ânus. Assim, se compõe uma série: sem órgão-órgão indeterminado polivalente-órgãos temporários e transitórios." (DELEUZE, 1984, p.34, 35) 
Deleuze vem então afirmar que esta série completa é a realidade do corpo histérico. Basta se reportar ao quadro da histeria que se forma no século XIX - as célebres contraturas e paralisias, as hiperestesias, os fenômenos de precipitação sempre alternantes e migrantes segundo os efeitos da passagem da onda nervosa segundo as zonas que ela investe (idem, p.35).

O silêncio sobre o fato de que é o discurso freudiano quem ousa cartografar esse corpo máquina desejante que causava frisson nas apresentações de Charcot, soa ao nossos ouvidos como uma provocação, que nos convida a agenciar a definição de Deleuze do corpo sem órgãos da histeria como "uma série: sem órgão órgão indeterminado polivalente — órgãos temporários e transitórios" com as formulações de Freud em 1893 nos Estudos comparativos entre as paralisias orgânicas e histéricas: "Eu afirmo que a lesão das paralisias histéricas é totalmente independente da anatomia dos sistemas nervosos, posto que a histeria se comporta nessas paralisias como se a anatomia não existisse ou como se ela a desconhecesse” (FREUD, 1984, p.55). "O sintoma histérico remete a uma outra realidade do corpo, expressando uma realidade intensiva: o braço paralisado não remete a uma lesão funcional, sendo expressão de um valor afetivo que lhe é conferido" (idem, p.57). Freud vem assim revelar as cartografias inéditas, singulares que a histeria modula em seu corpo, segundo as ondas de intensidade e de afeto que o atravessam.

Para além do debate Édipo / Anti-Édipo, em que medida poderíamos considerar o Anti-Édipo — em sua potente afirmação de diferença — como um dos mais vigorosos agenciadores de linhas conceituais de intensidade presentes no texto freudiano?

Recebido em 26/2/2003. Aprovado em 9/6/2003 


\section{REFERÊNCIAS}

ARÁN, M. (2000) Feminilidade, entre psicanálise e cultura: Esboços de um conceito, in: Physis Revista de Saúde Coletiva, n.1, v. 10. Rio de Janeiro, p.169-195.

. (2002) "A singularização adiada: O feminino na civilização moderna”, in BIRMAN, J. (org.) Feminilidades. Rio de Janeiro: Contra Capa.

BIRMAN, J. (1996) Por uma estilística da existência. São Paulo: Editora 34. (1999) Psicanálise, negatividade e heterogêneo; como a psicanálise pode ser obstáculo para a barbárie, in Cadernos da Psicanálise n. 18, v.15. Rio de Janeiro, p.89-107.

BORCH-JACOBSEN. (1989) Le sujet freudien, du politique à l'éthique, in Cahiers Confrontation, 20. Paris: Aubier.

CAVALCANTI, M. (2000) Freud e a physis: materialidade e subjetividade, in Revista Brasileira de Psicanálise: n.1, v.34. Rio de Janeiro.

DA COSTA, R. \& GONDAR, J. (1995) "Vídeo-entrevista com Felix Guattari”, in As pulsões. MOURA, Arthur Hipólito de (org.). São Paulo: Escuta.

DAVID-MÉNARD, M. (1983) L'hystérique entre Freud et Lacan; corps et language en psychanalyse. Paris: Editions Universitaires. . (2000) Tout le plaisir est pour moi. Paris: Hachette.

DELEUZE, G. (1984) Francis Bacon, Logique de la sensation. Paris: Editions de la Différence.

. (1987) Proust e os signos. Rio de Janeiro: Forense.

(1983) Apresentação Sacher-Masoch. Rio de Janeiro: Taurus.

\& GUATTARI, F. (1976) O Anti-Édipo Rio de Janeiro: Imago.

(1992) O que é filosofia? São Paulo: Editora 34.

FORTES, I. (2000) "O sentido do sofrimento: a positividade da dor em Freud”. Tese de doutorado em teoria psicanalítica. Rio de Janeiro: UFRJ/Instituto de Psicologia.

FOUCAULT, M. (1983). “Qu’est-ce qu’un auteur?”, Littoral. Paris: Erés, n. 9 , juin.

. (1976) Histoire de la Sexualité, v.1, La Volonté de savoir. Paris: Gallimard.

FREUD, S. (1895/1979) “Exquisse d'une Psichologie Cientifique”, in Naissance de la Psychanalyse. Paris: PUF.

(1893/1984) Études comparatives de paralysies motrices organiques et histériques, in Resultats, Idées, Problèmes, I. Paris: PUF.

. (1905/1987) Trois Essais sur la théorie sexuelle. Paris, Gallimard.

(1915/1968) "Pulsion e destins de la pulsion", in La Metapsychologie. Paris: Gallimard.

(1920/1983) “Au-delà du Principe du Plaisir”, in Essais de Psychanalyse. Paris: Payot.

NERI, R. (1999) “Modernidade: O encontro histórico da psicanálise com a histeria”. Tese de doutorado em teoria psicanalítica. Rio de Janeiro: UFRJ/Instituto de Psicologia. 
(2002) "O encontro entre a psicanálise e o feminino: singularidade e diferença”, in BIRMAN, J. (org.) Feminilidades. Rio de Janeiro: Contra Capa.

(2002) "O teatro da histeria: subversão do sujeito da razão", in Lições de Psicanálise 19 FACCHINETTI, C. (org.). Rio de Janeiro, UniverCidade.

ORLANDI, L. B. L. (1995) “Pulsão e campo problemático”, in MOURA, Arthur Hipólito de (org.). As pulsões. São Paulo, Escuta.

(2002). Corporeidades em minidesfile (mimeo).

PELBART, P. P. (2000) A vertigem por um fio. São Paulo, Iluminuras.

PONTALYS, J. B. (1994) L’inachévement, in Nouvelle Revue de Psychanalyse. Paris: Gallimard, n.50.

RAJCHMAN, J. (1994 ) Eros e verdade. Lacan, Foucault e a questão da ética. Rio de Janeiro, Jorge Zahar.

SWAIN, G. (1986) "A alma, a mulher, o sexo e o corpo. As metamorfoses da histeria no fim do século XIX”, in BIRMAN, J. e NICÉIAS, C. A. (orgs.). Teoria da prática psicanalítica. Rio de Janeiro: Campus.

SCHNEIDER, M. (1980) Freud et le plaisir. Paris: Denoel. abril. (1992) Entre nature et culture, le cri. Études Freudiens. Paris: (2000) Genéalogie du Masculin. Paris: Aubier.

\footnotetext{
Regina Neri

Rua Décio Vilares, 229/401

22041-040 Rio de Janeiro RJ

Telefax (21) 2547-8838

reginaneri@uol.com.br
} 